\title{
Dynamic Cerebral Microdialysis during Pallidotomy and Thalamotomy in Parkinson's Disease: A Preliminary Neurochemical Study
}

\author{
Sergio A. Sacchettoni1,2, Juan P. Abud1, Napoleon Torres3 ${ }^{3}$ Yngo García ${ }^{1,4}$, Daniel A. Onay¹, \\ Juan Luis Rodulfo' ${ }^{1}$, Juan Félix Del Corral ${ }^{2}$, Pedro Rada ${ }^{4}$, Rafael Galera ${ }^{1,2}$, Luis Hernández ${ }^{4}$ \\ ${ }^{1}$ Service of Neurosurgery, Hospital and School of Medicine JJ Vargas, Universidad Central de Venezuela, Caracas, Venezuela \\ ${ }^{2}$ Unit of Surgical Research, Hospital and School of Medicine JJ Vargas, Universidad Central de Venezuela, Caracas, Venezuela \\ ${ }^{3}$ Univ. Grenoble Alpes, CEA, LETI, Clinatec, France \\ ${ }^{4}$ Laboratory of Behavioral Physiology, Faculty of Medicine, Universidad de Los Andes, Mérida, Venezuela \\ Email:nmsa@neurologymobile.com
}

How to cite this paper: Sacchettoni, S.A., Abud, J.P., Torres, N., García, Y., Onay, D.A., Rodulfo, J.L., Corral, J.F.D., Rada, P., Galera, R. and Hernández, L. (2020) Dynamic Cerebral Microdialysis during Pallidotomy and Thalamotomy in Parkinson's Disease: A Preliminary Neurochemical Study. Open Journal of Modern Neurosurgery, 10, 284-296.

https://doi.org/10.4236/ojmn.2020.102031

Received: January 10, 2020

Accepted: April 19, 2020

Published: April 22, 2020

Copyright $\odot 2020$ by author(s) and Scientific Research Publishing Inc. This work is licensed under the Creative Commons Attribution International License (CC BY 4.0).

http://creativecommons.org/licenses/by/4.0/

(c) (i) Open Access

\begin{abstract}
In Parkinson's disease (PD), dopaminergic neurons reduce the regulation of glutamatergic (glutamate-Glu) input from the cortex to neostriatum (caudate and putamen nuclei) consequently leading to a hyperactivity of globus pallidus internae (GPi) neurons that release gamma-amino-butyric acid (GABA) into the thalamic ventrolateral (VL) nucleus. The objective of the present experiment was to measure changes in GABA and Glu in the caudate and the thalamus of 2 patients during the application of electrical stimuli following either a pallidotomy or a thalamotomy. Proper insertion of the electrode was tested by applying high frequency electrical pulses (HFEP). During these procedures, we obtained neurochemical information placing cerebral (CMD) microdialysis probes in caudate nucleus and VL nucleus of ipsi- and contra-lateral thalamus. In VL thalamus, extracellular GABA decreased during HFEP, tending to reach previous levels once HFEP was finalized. Following the pallido- or thalamotomy GABA decreased again. Similarly, in the contralateral VL thalamus, extracellular GABA levels showed a similar but less pronounced profile but did not show any decrement after the lesion. Caudate Glu decreases when HFEP is applied to the GPi and recovers to previous levels after HFEP, but did not decrease again after lesion (GPi-tomy), instead it continued to rise. These results suggest that HFEP exerts a similar but reversible biochemical effect as thermopallido- or thermothalamotomy on GABA extracellular concentration in the ipsilateral VL thalamus. We also observe a distant effect of HFEP, but not of thermolesion, on contralateral thalamic GABA and ipsilateral caudate Glu.
\end{abstract}




\section{Keywords}

Cerebral Microdialysis, Parkinson's Disease, Pallidotomy, Thalamotomy, Basal Ganglia Circuit, Cerebral Electromodulation, DBS

\section{Introduction}

Parkinson's disease (PD) affects between $0.4 \%$ and $0.6 \%$ of the Venezuelan population (morbidity of Ministry of Health, 2013 and 2017).

Surgical therapies for PD include ablative procedures as pallidotomy [1] [2] and thalamotomy [3] and more conservative surgery as deep brain stimulation (DBS) [4] [5], although we prefer the term of deep brain electrical modulation (DBEM). Application of electrical pulses was used in the past to verify the correct placement of instruments in awake patients during surgery [6]. Generally, low frequency $(<8 \mathrm{~Hz})$ electrical pulses induced neural excitation and exacerbated symptoms or signs corresponding to the targeted region, whereas high frequency $(>100 \mathrm{~Hz})$ electrical pulses mimicked the effect of lesion and suppressed these symptoms and signs [6] [7]. The mechanisms responsible for this phenomenon are not clear. Some hypotheses include: 1) high frequency electrical pulses (HFEP) may silence the activity of neurons in the globus pallidum internae (GPi) or in the subthalamic nucleus (STN) neurons by a "depolarization block" [8] [9]; 2) HFEP may reshape the abnormal pattern of activity of the basal ganglia output nuclei [10] [11].

A pathophysiological hypothesis of the basal ganglia that attempted to explain PD and dyskinesias was suggested two decades ago by De Long [12] [13] [14]. The circuitry is schematically illustrated in Figure 1. For the purposes of this

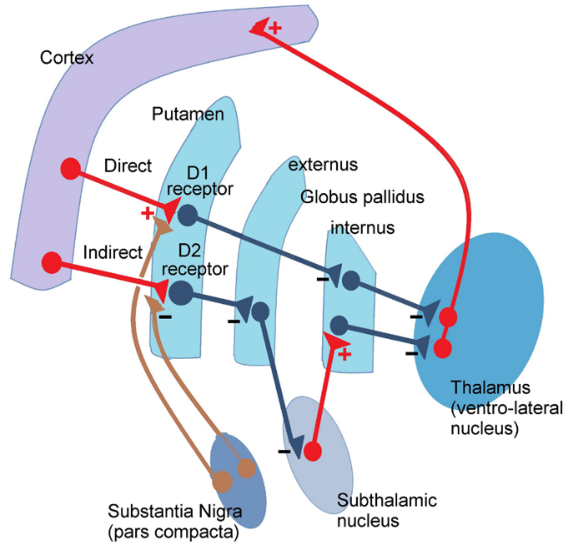

(a)

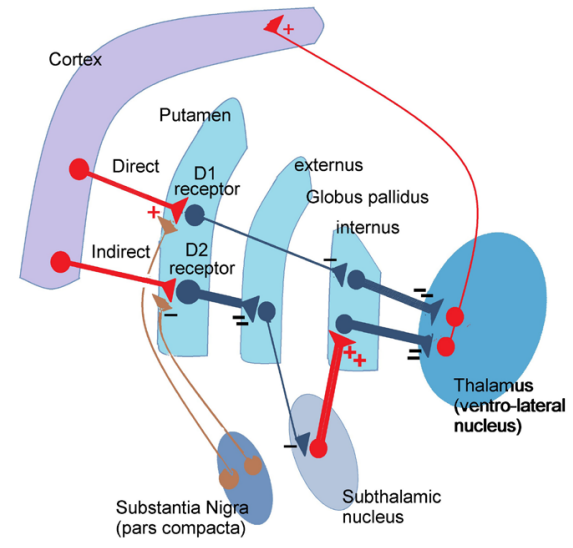

(b)

Figure 1. Basal ganglia motor circuitry hypothesis proposed by De Long. (a). Normal. neostriatum (caudate and putamen nuclei) receive glutamatergic (glutamate-Glu) input from the cortex. The thalamus receives GABA input from the globus pallidum internae (Gpi) nucleus. (b). Parkinson's disease. Due to lack of dopamine in the basal ganglia circuits the resulting GABA, released by Gpi afferent, is higher. 
work, we will only remark that, according to this model, neurons in the neostriatum (caudate and putamen nuclei) receive glutamatergic inputs from the cortex, and ventro-lateral (VL) thalamus neurons receive GABAergic inputs from the Gpi.

Intracerebral microdialysis has been extensively studied in Mérida, Venezuela [15] [16] [17] [18] [19] and the group of Ungersted [20] [21] (Lund, Sweden). We applied this technique used in Mérida to obtain more information about the neurochemistry of the basal nuclei circuitry and the mechanisms probably involved during HFEP and thermolesion. To do this, a microdialysis probe was placed in the caudate nucleus and ventro-lateral thalamus (bilateral) in two PD patients, during a left pallidotomy (coagulation of the GPi, patient 1) or a left thalamotomy (coagulation of the Vim nucleus, patient 2). Variations in glutamate and gamma-amino-butyric acid (GABA) were monitored with and without the application of HFEP and after radiofrequency coagulation. Microdialysates were collected adjacent to the electro-modulated/coagulated site, or distal to it (as in VL, being the GPi the electro-modulated/coagulated site) (Figure 2).

\section{Patients, Material and Methods}

\subsection{Patients}

All procedures were approved by the ethical standards of the Ethical Committee on human experimentation of the Hospital Vargas de Caracas. Patients agreed with this study and signed a written informed consent. The surgical technique was published elsewhere [22] [23]. Parkinsonian patients chose for surgery must comply with the following criteria: having a Hoehn and Yahr (H\&Y) scale grade 4 or 5; more than 5 years of diagnostic, a stable evolution (no more than 1 grade worst of $H \& Y$ scale in those 5 years). A left stereotactic Laitinen's pallidotomy (postero-ventro-lateral pallidotomy) was performed in a male patient aged 49 (Patient 1), who presented predominant right PD with rigidity and L-dopa induced dyskinesia.

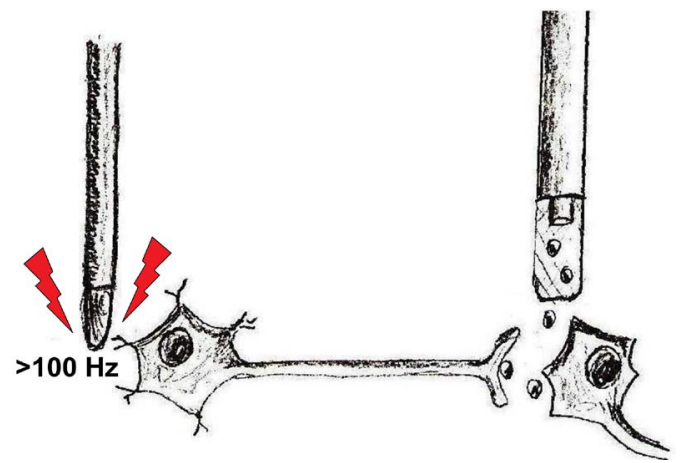

Figure 2. Placement of the microdialysis probe. The microdialysis probes were placed either at the same nucleus of the operating electrode (electrical pulses/radiofrequency) or at a distant nucleus, as depicted in the figure. 
A second patient (Patient 2), female, aged 54, suffering PD with predominant tremor in the right side of her body, underwent left stereotactic Leksell's thalamotomy (thermolesion of the ventral intermediate nucleus -Vim-). In both patients, cerebral microdialysis was performed. Schematic method is illustrated in Table 1.

Patient procedures were authorized by the Technical Commission of the Hospital and followed the FONACIT (Fondo Nacional para la Ciencia y la Tecnología) and the Institute of Biomedicine ethical rules:

(http://www.fonacit.gob.ve/documentos/bioetica2009.pdf http://www.biomedicina.org.ve/portal/comite-de-bioetica.html).

\subsection{Surgical Procedures}

A Micromar stereotactic frame (TM system;, Micromar, Sao Paulo, Brasil) was placed into the patient's head, under local anesthesia. Patients were advised to withhold her/his anti-parkinsonian medication only early in the morning in order to avoid artifacts during magnetic resonance imaging (MRI) or computed tomography (TC) scanning. Targets (Vim, GPi) were calculated as follows: 1) Vim: $2 \mathrm{~mm}$ superior to the intercomissural (AC-PC) line, $4 \mathrm{~mm}$ posterior to the midpoint of the AC-PC line, $14 \mathrm{~mm}$ lateral to the midline; 2) Postero-ventro-lateral pallidal target (GPi): $5 \mathrm{~mm}$ inferior to the AC-PC line, $3 \mathrm{~mm}$ anterior to the mid AC-PC line, $21 \mathrm{~mm}$ lateral to the midline. Targets were confronted with previous magnetic resonance images (MRI). Once the target point was calculated, patients were brought to the operating room. Under local anesthesia, a bilateral burr hole is performed $2 \mathrm{~cm}$ away from the midline and $1 \mathrm{~cm}$ anterior to the coronal suture. The electrode is placed $1.5 \mathrm{~cm}$ above the target, GPi or Vim. Microdialysis probes are introduced to the ventral thalamus in both sides, $4 \mathrm{~mm}$ diagonally (along the longitudinal axis of the thalamus) in front of the Vim, and to the head of the left (ipsi-lateral) caudate nucleus (Figure 3). Coordinates of the caudate nucleus are calculated referring to the center of the

Table 1. Schematic methodology. We report 2 preliminary Parkinson patients having been studied with intracerebral microdialysis. Gpi globus pallidum internae; Vim Ventral intermedia nucleus of the thalamus; $V L$ Ventrolateral complex of the thalamus; $C M D$ cerebral microdialysis; HFEM high frequency electrical modulation.

\begin{tabular}{|c|c|c|}
\hline \multicolumn{3}{|c|}{ GENERAL OUTLINE OF METHODS } \\
\hline \multicolumn{3}{|c|}{ Parkinson predominantly right side } \\
\hline & Patient 1 (male) & Patient 2 (female) \\
\hline & $\begin{array}{l}49 \text { yo Predominant rigidity and } \\
\text { L-dopa-induced dyskinesia-right } \\
\text { side }\end{array}$ & $\begin{array}{l}54 \text { yo Predominant } \\
\text { tremor-right side }\end{array}$ \\
\hline Lesion (target) & Left pallidotomy (Gpi) & Left thalamotomy (Vim) \\
\hline $\begin{array}{l}\text { Electric pulses during } \\
\text { surgery (HFEM) }\end{array}$ & Left Gpi & Left Vim \\
\hline CMD & -VL bilaterally-Left caudate & -VL bilaterally-Left caudate \\
\hline
\end{tabular}




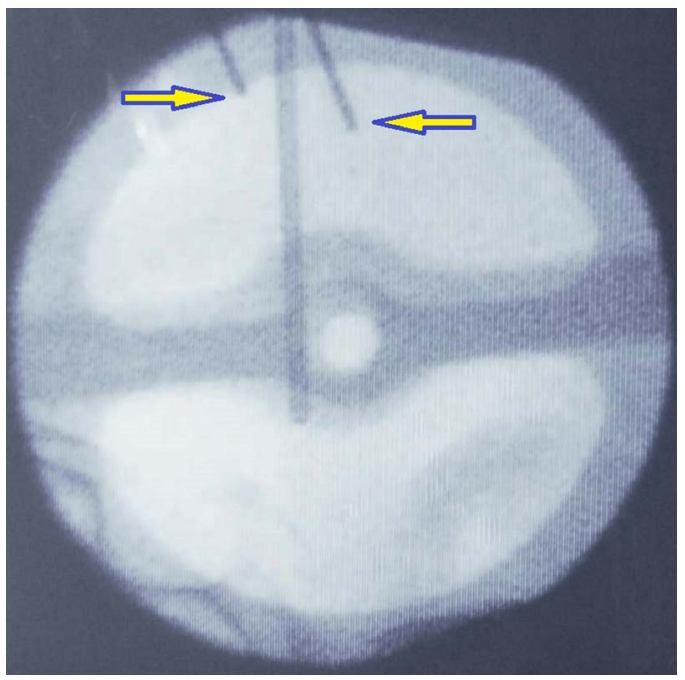

Figure 3. Intraoperative fluoroscopic view of the operating electrode and 2 of the microdialysis probes. Operating (stimulation-lesion) electrode is already placed in ventral intermedia nucleus of the thalamus (Vim). Microdialysis probes are seen above. One of them will be descended to the ventrolateral thalamic complex (VL), $4 \mathrm{~mm}$ in front of Vim nucleus.

image of the head of this nucleus, seen in the computed tomography, at the same plane of Vim nucleus.

Microdialysis probes were perfused with a sterile solution $(135 \mathrm{mM} \mathrm{NaCl}, 3.7$ $\mathrm{mM} \mathrm{KCl}, 1.0 \mathrm{mM} \mathrm{MgCl}_{2}, 1.2 \mathrm{mM} \mathrm{CaCl}_{2}$ and $10 \mathrm{mM} \mathrm{NaHCO}_{3}, \mathrm{pH} 7.4$ ) at a flow rate of $1 \mathrm{microL} / \mathrm{min}$ in order to obtain basal levels. Sampling was started 30-min following the probe implantation, which is the time considered necessary to equilibrate extracellular neurotransmitter post-insertion.

Microdialysates were collected every $5 \mathrm{~min}$. Sampling consisted of 2 basal samples, 1 sample during HFEP, 2 samples post-HFEP and 2 final samples following radiofrequency coagulation. Once basal samples were collected, electrodes were then advanced until target region (GPi or Vim) was reached. Impedance was measured during electrode advance and HFEP was applied (1 - 4 volt, $110 \mathrm{~Hz}$ ) to confirm electrode position once the target was reached and 1 sample was taken at this moment as previously noted. When the position of electrodes was definitive and after two 5-min samples were taken post-HFEP, a thermolesion was performed, $75^{\circ} \mathrm{C}$ for $60 \mathrm{~min}$, and 2 final samples were taken.

\subsection{Sample Preparation and Analysis}

Standard derivatization of samples was obtained with optimal FITC/GABA relation of GABA [24], and FITC/Glu relation for Glu $(17,19)$, as previously published.

A Meridialysis CZE ${ }^{\circ}$ system (model 3ZPO, Mérida, Venezuela) equipped with an argon laser was used for measurement of samples, using the capillary elec- 
trophoresis and laser-induced fluorescence detection [19] [25] (Figure 4). Results are expressed in percentage, related to the mean of the first 2 (basal) samples taken as $100 \%$.

\section{Results}

In patient 1 (left Gpi-tomy) right dyskinesia disappeared progressively in the following weeks, and remained absent with a follow-up of 3 years. Patient 2 (Vim-tomy) had a transient right hemiparesis, probably due to peri-coagulation edema since it only lasted 1 week post-operatively. She immediately showed cessation of tremor at surgery, however, a mild tremor reappeared 6 months later, which could be controlled by medication.

GABA levels were measured in the ventro-lateral (VL) thalamus in both sides and Glu levels were measured in the left caudate nucleus in both patients.

\subsection{GABA Levels in Ipsilateral Thalamus}

In patient 1 (GPi-tomy) when HFEP was applied in Gpi, extracellular levels of GABA in VL-thalamus (GABA-VL) decreased and tended to regain previous levels when HFEP were halted. A similar profile of GABA-VL was observed in patient 2 (Vim-tomy) when HFEP were applied to the ipsilateral Vim. But the recuperation of the previous GABA-VL levels was slower when HFEP stopped in this patient (Figure 5). After thermolesion, both patients showed a decrement of GABA-VL levels.

\subsection{GABA Levels in Contralateral Thalamus}

In contralateral VL, extracellular GABA-VL levels showed a similar but less marked profile, i.e. diminution of GABA levels, although less abruptly, during HFEP, and regained previous levels after HFEP stopped; but did not show any decrement after lesion. In fact, after lesion, GABA levels continue to rise. It

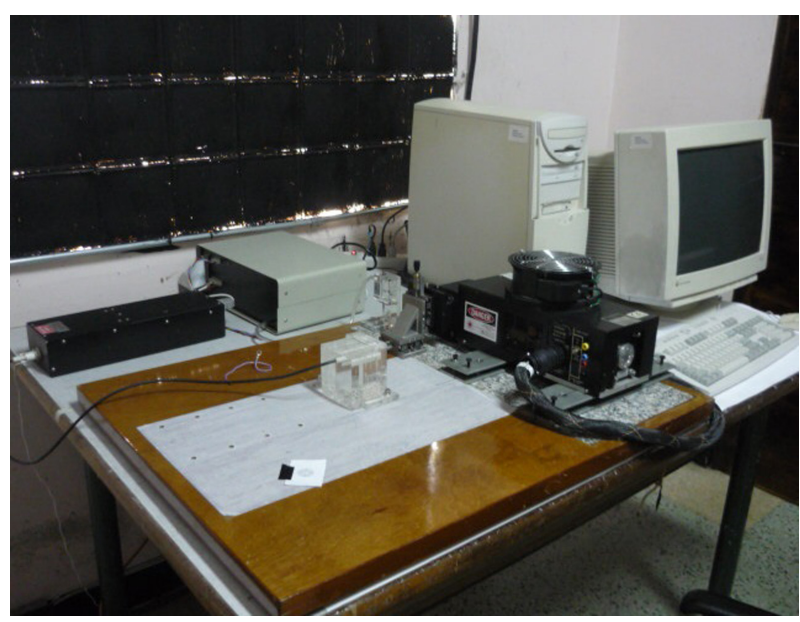

Figure 4. Meridialysis $\mathrm{CZE}^{\circ}$ system (model $3 \mathrm{ZPO}$ ). It is equipped with an argon laser to induce fluorescence from samples that run through capillary electrophoresis. 

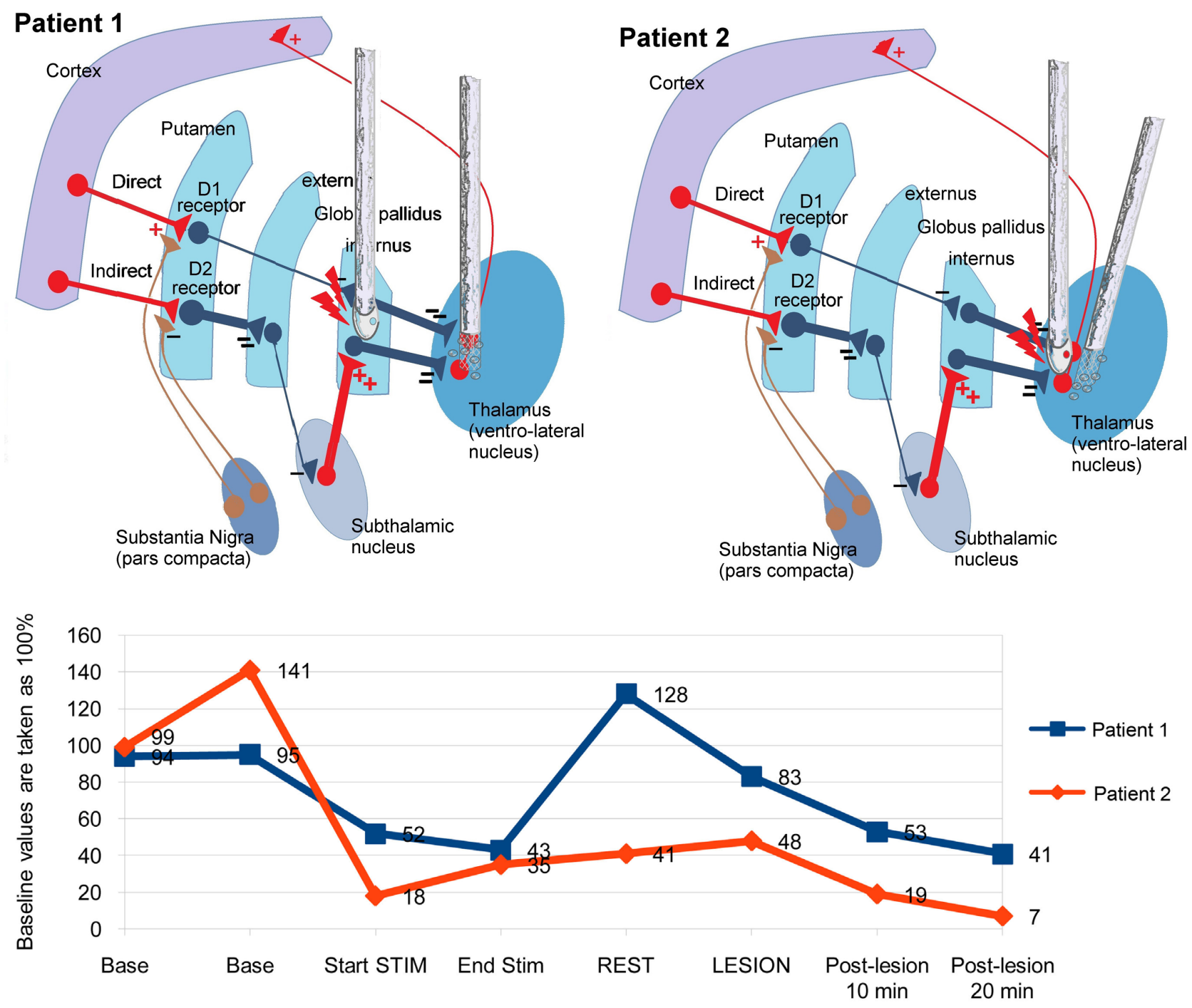

Each division represents $5 \mathrm{~min}$

Figure 5. GABA in ipsilateral thalamus. Above there is a schematic description of the methodology of each patient: EM, site of electro-modulation and thermo-coagulation by radiofrequency; cerebral microdialysis (CMD), site of cerebral microdialysis. Below are the levels of GABA in the ventrolateral (VL) nucleus of thalamus, expressed in percentage of baseline values (100\%), during application of high frequency electrical pulses (HFEP) and after lesion. GABA in thalamus decreases during HFEP and after lesion.

seems that HFEP indirectly affects contralateral thalamus, but not the thermolesion (Figure 6).

\subsection{Glu Levels in Ipsilateral Caudate Nucleus}

Glu levels were measured in the left (ipsilateral) caudate nucleus (Figure 7). Glu levels in patient 1 (GPi-tomy) showed a slight decrease during HFEP in GPi, but after GPi-tomy Glu levels showed a discrete increase. In Patient 2 (Vim-tomy), changes in extracellular GLU were opposite to those observed in patient 1. Glu concentrations increased progressively during HFEP, and regained previous levels after HFEP. Following Vim-tomy, Glu levels showed an initial increase and 


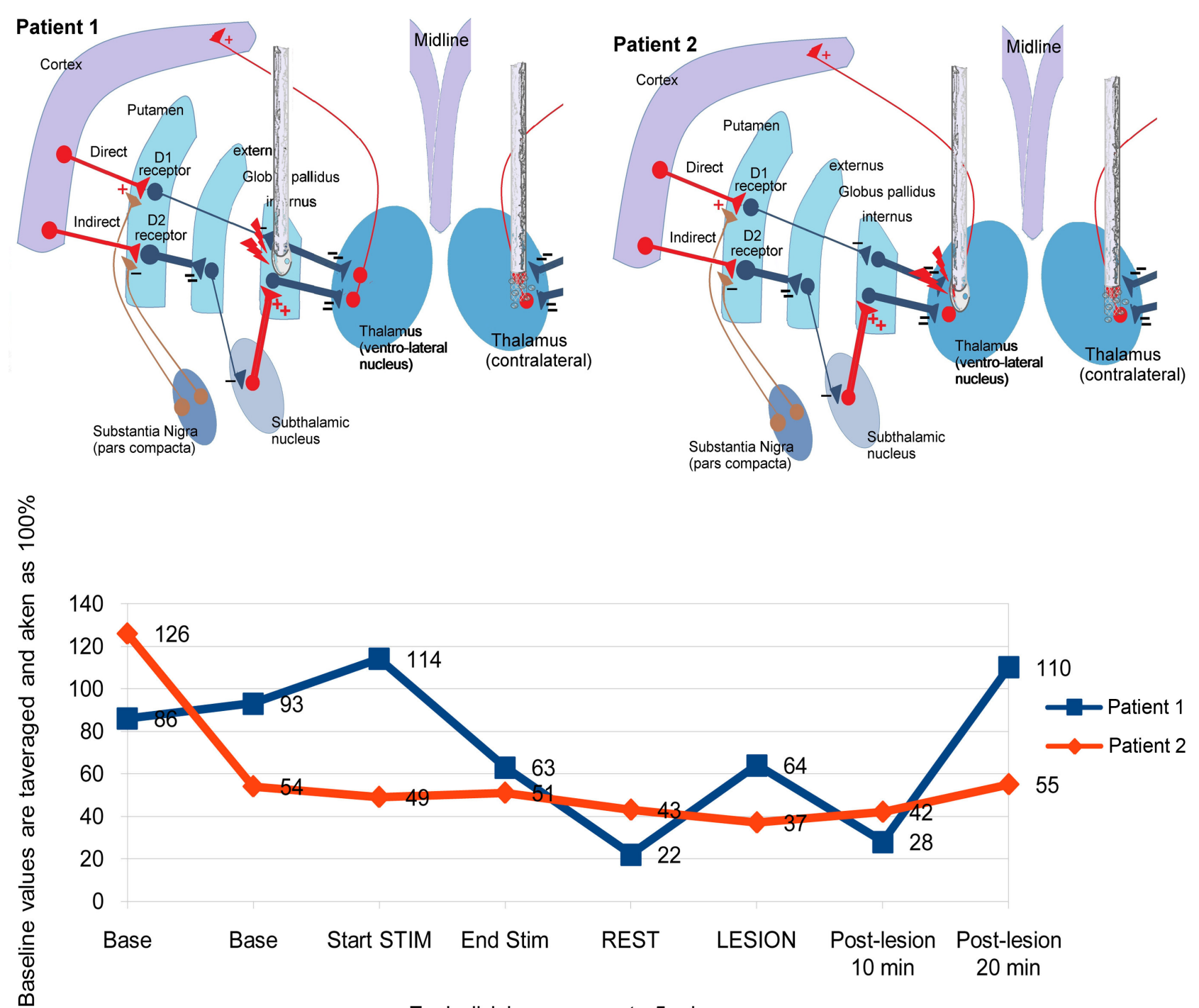

Each division represents 5 min

Figure 6. GABA in contralateral thalamus. Above there is a schematic description of the methodology of each patient: site of electro-modulation (EM) and thermo-coagulation by radiofrequency, site of cerebral microdialysis (CMD). Below are the levels of GABA of contra-lateral thalamus (VL), expressed in percentage of initial value (basal), during application of high frequency electrical pulses (HFEP) and after lesion. GABA in contra-lateral thalamus diminishes only during HFEP and not after lesion.

a subsequent decrease. We observed again an effect in a distant nucleus.

\section{Discussions}

According to the accepted model of the basal ganglia pathophysiology [12] [13] [14], we found that, indeed, VL-thalamic GABA levels are higher than after the surgical correction, as it would be expected. We cannot be sure if levels were higher than normal, since we lack any control of thalamic GABA levels. However, GABA levels decreased during HFEP. Once HFEP stopped, GABA concentration regained basal levels in the next sample 5 minutes later. After GPi thermolesion, levels decreased once again. The same response seems to happen if HFEP and thermolesion were applied in Vim nucleus. If GABA levels decrease 

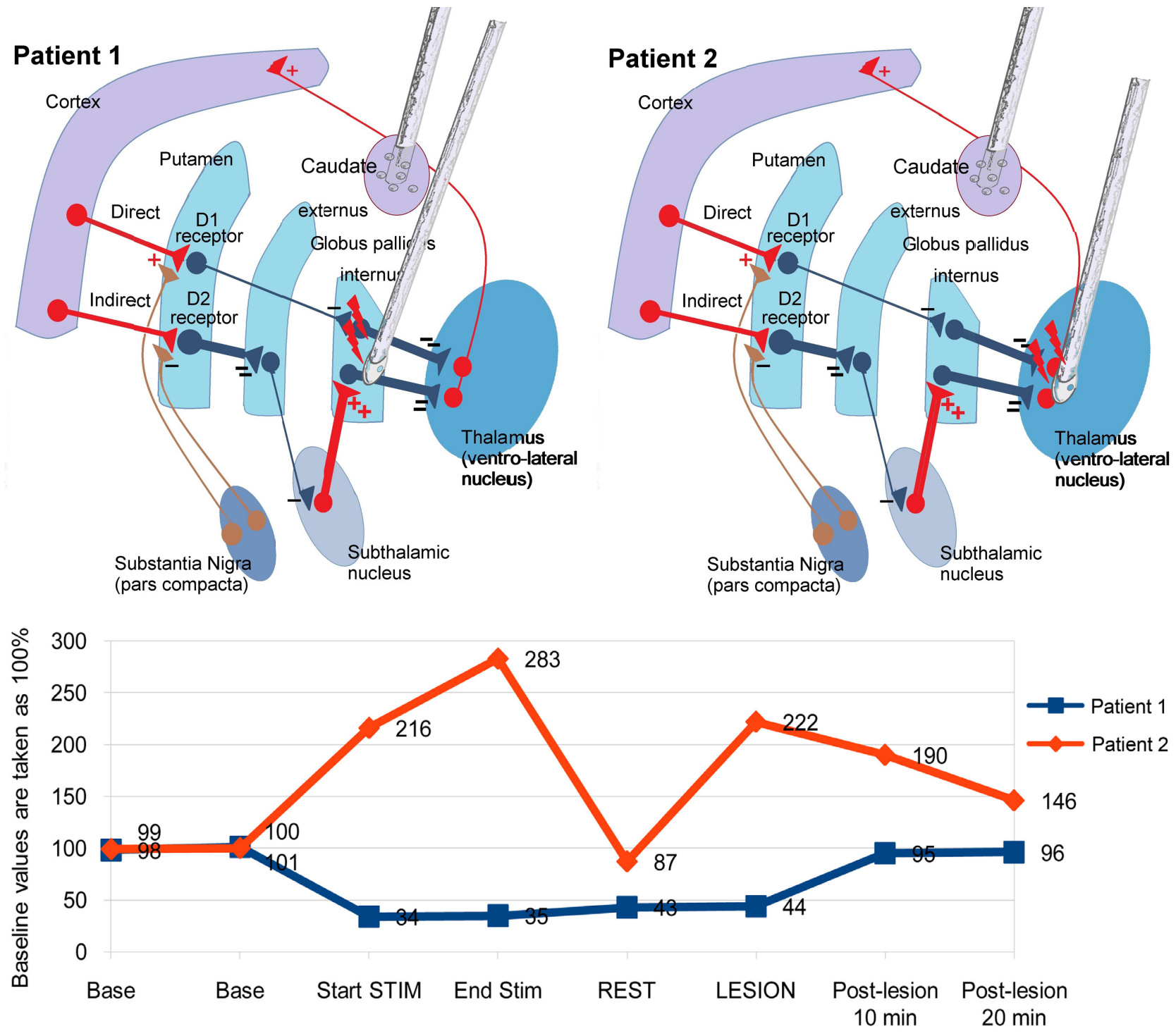

Each division represents $5 \mathrm{~min}$

Figure 7. Glutamate in caudate nucleus. Above is a schematic description of the methodology of each patient: site of electro-modulation (EM) and thermo-coagulation by radiofrequency, site of cerebral microdialysis (CMD). Below are the levels of Glu of caudate nucleus, expressed in percentage of initial value (basal), during application of high frequency electrical pulses (HFEP) and after lesion. Glu levels vary depending whether the site of HFEP was GPi or Vim. In each case, Glu levels are affected distinctly between HFEP and lesion. It is to note that HFEP can affect a site distant to the site of its application.

after these 2 procedures, which are indeed inhibitory, we may infer that GABAergic pallidal neurons stopped firing (decreased activity) in both GPi or Vim during HFEP or after thermolesion. Thus, thermolesion or HFEP, lesioned or inhibited GABAergic pallidal neurons, specifically their axons in the thalamus or the soma in Gpi. This suggests that HFEP exerted a similar biochemical effect as thermolesion did on GABA extracellular concentration in the ventro-lateral thalamus, and that it is reversible. Interestingly, GABA levels of the contralateral thalamus decrease with HFEP, but not after thermolesion. We do not know at present whether these phenomena can be reflected in clinical outcome after chronic 
HFEP (or best known as DBS), but in any case, we observed a distal and trans-hemispheric effect of HFEP.

In the caudate nucleus, which constitutes part of the neostriatum, and thus belongs to the entry site of the basal ganglia circuitry, we found different neurochemical scenarios depending upon whether HFEP or thermolesion was applied. GABA was undetectable, but Glu, which is normally released by afferences from the cortex, was measured. Glu levels show a decrement during HFEP in GPi. These data may suggest, although not enough to be sure, that HFEP in the GPi might exert an inhibitory effect in cortico-striatal pathway, arriving to caudate nucleus, perhaps by antidromic effect. Conversely, after HFEP finalized, Glu levels increased and remained so during and after thermolesion, demonstrating, once more, that HFEP is able to exert an effect in distant nuclei. The capacity of HFEP in exerting a remote effect was also found in animal experiments in previous works [26] and other authors explained that HFEP might recruit other fiber systems at the level of the STN [27] [28] [29].

The mechanism by which HFEP exerts an inhibitory effect is not well known. Many hypotheses have arisen and remain to be verified. It has been proposed that inhibitory neurotransmitters are also released along with excitatory neurotransmitters resulting in an inhibitory final effect [30]. HFEP could also override abnormally patterned activity instead of inhibition [30]. This can be interpreted as if the neurons start firing in a frequency that disturbs normal depolarization, thus leading to "no depolarization" or "depolarization block" [8] [9], and thus avoiding any transmission of signal. Recently, it was suggested that globus pallidus neurons are normally desynchronized and their activity becomes synchronized in Parkinson's disease, thus HFEP may induce chaotic desynchronization by interacting with the intrinsic oscillatory mechanism of globus pallidus neurons [31]. These authors suggest a mechanism of action of HFEP in which synchrony, rather than firing rate, is the critical pathological feature. This might partly explain the HFEP mechanism.

Direct neurochemical demonstration of the hypothetical physiopathology of the basal ganglia in humans was not published before. These observations reinforce this hypothetical model. We did not find any previous report of CMD performed in surgery, during application of stimuli, i.e., or during electrophysiological tests. We call this "dynamic microdialysis".

This study can help in assessing the relevance of CMD. Further work, on a longer series, could give evidence to justify $\mathrm{CMD}$ as a tool in neurosurgery that can aid in precise diagnosis, thus guiding better functional neurosurgical interventions, and a mean to better understand the pathophysiology in Parkinson's disease.

\section{Note}

Our experience in stereotactic functional neurosurgery began in the Hospital Vargas in the late 60s, after neurosurgical training in Professor Lars Leksell's 
Department at the Karolinska Hospital by two of the authors [32] [33]. Clinical experiences in this field are continuously in progress with the aim to improve functional neurosurgery in Venezuela.

This work is part of a Doctorate Thesis in Neurosciences, Universidad de Los Andes of Juan Pointcare Abud.

Napoleon Torres is now working at the CEA (Atomic Energy and Alternative Energies Commission)-LETI-CLINATEC, Grenoble, France.

\section{Acknowledgements}

We thank Dr Edgar González, chief of Service at the time of this work, who provided all support for its achievement.

\section{Conflicts of Interest}

The authors declare no conflicts of interest regarding the publication of this paper.

\section{References}

[1] Laitinen, L.V. (1995) Pallidotomy for Parkinson's Disease. Neurosurgery Clinics of North America, 6, 105-112. https://doi.org/10.1016/S1042-3680(18)30479-0

[2] Teive, A.G. and Meneses, M.S. (1996) Histórico. In: Teive and Meneses, Eds., Doença de Parkinson, aspectos clínicos e cirúrgicos, Editora Guanabara Koogan, Río de Janeiro, 4-14.

[3] Hassler, R. and Reichert, T. (1954) Indikationen und Lokalisationsmethode der gezielten Hirnoperationen. Nervenarzt, 25, 441-447.

[4] Benabid, A.L., Pollak, P., Gervason, C., Hoffmann, D., Gao, D.M., Hommel, M., Perret, J.E. and de Rougemont, J. (1991) Long-Term Suppression of Tremor by Chronic Stimulation of the Ventral Intermediate Thalamic. The Lancet, 337, 401-406. https://doi.org/10.1016/0140-6736(91)91175-T

[5] Benabid, A.L., Pollak, P., Gao, D., Hoffmann, D., Limousin, P., Gay, E., Payen, I. and Benazzouz, A. (1996) Chronic Electrical Stimulation of the Ventralis Intermedius Nucleus of the Thalamus as a Treatment of Movement Disorders. Journal of Neurosurgery, 84, 203-214. https://doi.org/10.3171/jns.1996.84.2.0203

[6] Riechert, T. (1973) Stereotaxic Surgery for Treatment of Parkinson's Syndrome. In: Krayenbühl, H., Maspes, P.E. and Sweet, W.H., Eds., Progress in Neurological Surgery, Ed Krager, Basel, 5. https://doi.org/10.1159/000394336

[7] Velasco-Campos, F. (2009) Targets for Electrical Stimulation in Functional Neurosurgery. In: Sindou, M., Ed., Practical Handbook of Neurosurgery, Vol. 3, Springer Wien, New York, 215-234.

[8] Beurrier, C., Bioulac, B., Audin, J. and Hammond, C. (2001) High-Frequency Stimulation Produces a Transient Blockade of Voltage Gated Currents in Subthalamus Neurons. Journal of Neurophysiology, 85, 1351-1356. https://doi.org/10.1152/jn.2001.85.4.1351

[9] Magariños Ascone, C., Pazo, J.H., Macadar, O. and Buño, W. (2002) High-Frequency Stimulation of the Subthalamic Nucleus Silences Subthalamic Neurons: A Possible Cellular Mechanism in Parkinson's Disease. Neuroscience, 115, 1109-1117. https://doi.org/10.1016/S0306-4522(02)00538-9 
[10] Garcia, L., D’Alessandro, G., Bioulac, B. and Hammond, C. (2005) High-Frequency Stimulation in Parkinson's Disease: More or Less? Trends in Neurosciences, 28, 209-216. https://doi.org/10.1016/j.tins.2005.02.005

[11] Bar-Gad, I., Elias, S., Vaadia, E. and Bergman, H. (2004) Complex Locking Rather than Complete Cessation of Neuronal Activity in the Globus Pallidus of a 1-Methyl-4-Phenyl-1,2,3,6-Tetrahydropyridine-Treated Primate in Response to Pallidal Microstimulation. The Journal of Neuroscience, 24, 7410-7419. https://doi.org/10.1523/JNEUROSCI.1691-04.2004

[12] Albin, R.L., Young, A.B. and Penney, J.B. (1989) The Functional Anatomy of Basal Ganglia Disorders. Trends in Neurosciences, 12, 366-375. https://doi.org/10.1016/0166-2236(89)90074-X

[13] De Long, M.R. (1990) Primate Models of Movement Disorders of Basal Ganglia Origin. Trends in Neurosciences, 13, 281-285. https://doi.org/10.1016/0166-2236(90)90110-V

[14] Alexander, G.E. and Crutcher, M.D. (1990) Functional Architecture of Basal Ganglia Circuits: Neural Substrates of Parallel Processing. Trends in Neurosciences, 13, 266-271. https://doi.org/10.1016/0166-2236(90)90107-L

[15] Hernández, L., Páez, X. and Hamlin, C. (1983) Neurotransmitters Extraction by Local Intracerebral Dialysis in Anesthetized Rats. Pharmacology Biochemistry and Behavior, 8, 159-162. https://doi.org/10.1016/0091-3057(83)90356-8

[16] Hernández, L., Stanley, B.G. and Hoebel, B.G. (1986) A small, Removable Microdialysis Probe. Life Sciences, 39, 2629-2637. https://doi.org/10.1016/0024-3205(86)90119-0

[17] Hernández, L. and Joshi, N. (2000) L’electrophorese capillaire et la détection en fluorescence induite parlaser. Spectra, 153, 40-43.

[18] Hernández, L., Escalona, J., Verdaguer, P. and Guzmán, N.A. (1993) In Vivo Monitoring of Brain Glutamate by Microdialysis Coupled to Capillary Electrophoresis and Laser Induced Fluorescence Detection. Journal of Liquid Chromatography, 16, 2149-2160. https://doi.org/10.1080/10826079308019921

[19] Hernández, L., Verdeguer, P., Guzmán, N.A. and Joshi, N. (1993) Laser-Induced Fluorescence Detection for Capillary Electrophoresis: A Powerful Analytical Tool for the Separation and Detection of Trace Amounts of Analytes. In: Guzmán, N.A., Ed., Capillary Electrophoresis. Theory, Methodology, and Applications, Marcel Dekker, New York, 605-614.

[20] Ungerstedt, U. (1984) Measurements of Neurotransmitter Release by Intracranial Dialysis. In: Marsden, C.A., Ed., Measurement of Neurotransmitter Release in Vivo, Wiley, New York, 81-105.

[21] Ungerstedt, U. and Hallström, Å. (1987) In Vivo Microdialysis-A New Approach to the Analysis of Neurotransmitter in the Brain. Life Sciences, 41, 861-864. https://doi.org/10.1016/0024-3205(87)90181-0

[22] Del Corral, J.F., Hernández, L., Sacchettoni, S.A., García, Y., Onay, D., Teneud, L. and Rada, P. (2000) Microdiálisis cerebral en humanos: Experiencia en la enfermedad de Parkinson. Archivos del Hospital Vargas, 42, 93-96.

[23] Sacchettoni, S.A., Rada, P., Teneud, L., Galué, R., Abud, J.P. and Del Corral, J.F. (2010) Microdialisis cerebral, una herramienta promisoria para el estudio neuroquímico en Neurocirugía: Una descripción técnica. Neurotarget, 5, 30-43.

[24] Rada, P., Tucci, S., Teneud, L., Páez, X., Pérez, J., Alba, G., García, Y., Sacchettoni, S., Del Corral, J.F. and Hernández, L. (1999) Monitoring Gamma-Aminobutyric Acid in Human Brain and Plasma Microdialysates Using Micellar Electrokinetic 
Chromatography and Laser-Induced Fluorescence Detection. Journal of Chromatography B, 735, 1-10. https://doi.org/10.1016/S0378-4347(99)00386-2

[25] Guzmán, N.A., Hernández, L. and Advis, J.P. (1990) Analysis of Brain Constituents by Capillary Electrophoresis. In: Villafranca, J.J., Ed., Current Research in Protein Chemistry: Techniques, Structure, and Function, Academic Press Inc. Harcourt Brace Jovanovich, New York. https://doi.org/10.1016/B978-0-12-721955-4.50025-7

[26] Maurice, N., Deniau, J.M., Degos, B., Windel, F., Carcenac, C., Poupard, A. and Savasta, M. (2005) High Frequency Stimulation of the Subthalamic Nucleus: Electrophysiological and Neurochemical Aspects. In: Bolam, J.P., Ingham, C.A. and Magill, P.J., Eds., The Basal Ganglia VIII, Advances in Behavioral Biology, Springer Science \& Business Media, Inc., Berlin, Book, 56, 243-253. https://doi.org/10.1007/0-387-28066-9_22

[27] Dostrovsky, J.O. and Lozano, A.M. (2002) Mechanisms of Deep Brain Stimulation, Review. Movement Disorders, 17, S63-S68. https://doi.org/10.1002/mds.10143

[28] Vitek, J.L. (2002) Mechanisms of Deep Brain Stimulation: Excitation or Inhibition. Movement Disorders, 17, S69-S72. https://doi.org/10.1002/mds.10144

[29] McIntyre, C.C., Savasta, M., Walter, B.L. and Vitek, J.L. (2004) How Does Deep Brain Stimulation Work? Present Understanding and Future Questions. Journal of Neurophysiology, 21, 40-50. https://doi.org/10.1097/00004691-200401000-00006

[30] Starr, P.A., Vitek, J.L. and Bakay, A.E. (1998) Deep Brain Stimulation for Movement Disorders. Neurosurgery Clinics of North America, 9, 381-402. https://doi.org/10.1016/S1042-3680(18)30273-0

[31] Wilson, C.J., Beverlin, B. and Netoff, T. (2011) Chaotic Desynchronization as the Therapeutic Mechanism of Deep Brain Stimulation. Frontiers in Systems Neuroscience, 5, 50. https://doi.org/10.3389/fnsys.2011.00050

[32] Del Corral, J.F. and Galera, R. (1969) Estereotaxia Humana. Acta Médica Venezolana, 7-8, 235-239.

[33] Galera, R. and Del Corral, J.F. (1972) Cirugía de los Ganglios Basales. Gaceta Médica de Caracas, 3-4, 177-184. 